\title{
REPOSITÓRIO DE CONTEÚDO DIGITAL: UMA BIBLIOTECA DA HISTÓRIA DA EDUCAÇÃO MATEMÁTICA
}

\author{
Bruna Lima Ramos \\ Universidade Federal de São Paulo - Campus Guarulhos \\ bruna_lramos@hotmail.com \\ Claudia Regina Boen Frizzarini \\ Universidade Federal de São Paulo - Campus Guarulhos \\ claudiafrizzarini@gmail.com \\ Deoclecia de Andrade Trindade \\ Universidade Federal de São Paulo - Campus Guarulhos \\ deo.clecia.1@gmail.com
}

\begin{abstract}
RESUMO
Esse artigo tem o intuito de divulgar o armazenamento, preservação, difusão e usos de documentos e materiais relevantes à história da educação matemática, entre o período de 1890 e 1970, a partir do Repositório de Conteúdo Digital da História da Educação Matemática, uma biblioteca digital idealizada, produzida e mantida por integrantes del GHEMAT - Grupo de Pesquisa em História da Educação Matemática no Brasil, que desde sua criação em 2000, atua no desenvolvimento coletivo de projetos temáticos de pesquisa sobre educação matemática com a participação de pesquisadores de diversos estados e universidades brasileños. Esse Repositório constitui-se um espaço virtual para alocação de documentos digitalizados, inserido no sítio da Universidade Federal de Santa Catarina, a manutenção atual do Repositório veicula-se pelo projeto "A constituição dos saberes elementares matemáticos: a Aritmética, a Geometria e o Desenho no curso primário em perspectiva histórico-comparativa, 1890-1970" coordenado pelo Prof. Dr. Wagner Rodrigues Valente e financiado pelo CNPq. Resultados de pesquisas realizadas a partir dos documentos postos no Repositório possibilitam debates, de nível nacional, evidenciados pelas produções obtidas de alguns Seminários Temáticos do GHEMAT, cada Seminário resultou na elaboração de um livro. Desse modo podemos inferir que os estudos por meio dos documentos do Repositório proporcionam a escrita e divulgação de características da escola primária em tempos passados, seja de elementos da sua constituição, organização, espaço, seja referente ao ensino de saberes matemáticos, métodos de ensino, orientações pedagógicas e finalidades de ensino.
\end{abstract}

Palavras-chave: Repositório digital. História da educação matemática. Biblioteca digital. Documentos históricos. História comparada.

\section{REPOSITORY OF DIGITAL CONTENT: A LIBRARY OF HISTORY OF MATHEMATICS EDUCATION}

\begin{abstract}
This article aims to disclose the storage, preservation, dissemination and document uses and materials relevant to the history of mathematics education, in the period between 1890 and 1970, from the Digital Content Repository of the History of Mathematics Education, a digital library conceived, produced and maintained by members of the GHEMAT (in english,
\end{abstract}


Research Group of the History of Mathematics Education, in Brazil), which since its creation in 2000, operates in the collective development of thematic research projects about mathematics education, with researchers participation from several states and Brazilian universities. The repository constitutes a virtual space for allocation of scanned documents, inserted into the website of the Federal University of Santa Catarina, the repository is maintained by the project "The constitution of mathematical elementary knowledge: arithmetic, geometry and Drawing on primary education in historical and comparative perspective, 1890-1970 "coordinated by Prof. Dr. Wagner Rodrigues Valente and funded by CNPq. Results of research conducted from the documents placed in the repository enable debates in national level, as evidenced by the production obtained from some of GHEMAT Thematics Seminars, each seminar resulted in the preparation of a book. Thus we can infer that the studies through the Repository documents provide the writing and dissemination of primary school characteristics in times past, either elements of its creation, organization, space, either concerning the teaching of mathematical knowledge, teaching methods, pedagogical guidelines and teaching purposes.

Keywords: Digital Repository. History of mathematics education. Digital library. Historical documents. Comparative history.

\section{REPOSITORIO DE CONTENIDO DIGITAL: UNA BIBLIOTECA DE LA HISTORIA DE LA EDUCACIÓN MATEMÁTICA}

\section{RESUMEN}

Este artículo tiene como objetivo difundir el almacenamiento, conservación, difusión y el uso de documento y materiales relacionados con la historia de la educación matemática, en el período comprendido entre 1890 y 1970, por el Repositorio de Contenido Digital de la Historia de la Educación Matemática, una biblioteca digital concebida, producida y mantenida por los miembros de la GHEMAT - Grupo de investigación de la historia de la educación matemática en Brasil, que desde su creación en 2000, opera en el desarrollo colectivo de los proyectos de investigación sobre educación matemática con la participación de investigadores de varios estados y universidades brasileño. Este Repositorio constituye un espacio virtual para la asignación de los documentos escaneados, insertado en la página web de la Universidad Federal de Santa Catarina, el mantenimiento actual del Repositorio si transmite por el proyecto "La constitución del saberes matemáticos elemental: aritmética, geometría y dibujo en la escuela primaria en perspectiva histórica y comparativa, 1890-1970", coordinado por el Prof. Dr. Wagner Rodrigues Valente y financiado por el CNPq. Los resultados de las investigaciones realizadas a partir de mensajes en los documentos del repositorio permiten debates, a nivel nacional, como evidenciado por las producciones obtenidas de algunos Seminarios Temáticos del GHEMAT, cada seminario dio lugar a la preparación de un libro. De este modo se puede inferir que los estudios a través de los documentos del Repositorio proporcionan la redacción y difusión de características de la escuela primaria en el pasado, es elementos de su constitución, organización, espacio, ya sea en relación con la enseñanza de saberes matemáticos, métodos de enseñanza, orientaciones didácticas y propósitos de enseñanza.

Palabras clave: Repositorio Digital. Historia de la educación matemática. Biblioteca digital. Documentos históricos. Historia comparada. 


\section{CONSIDERAÇÕES INICIAIS}

A divulgação e o armazenamento de documentos históricos atualmente podem ser organizados e disponibilizados em formatos digitais, o que leva a representar um exemplo distinto dos documentos alocados em arquivos históricos e bibliotecas, muitas vezes de difícil acesso. Ao se tratar de documentos impressos, a interação entre fontes de distintas regiões se dificulta pela distância entre os locais de armazenamento. A disponibilização em meios digitais, como em CDs, DVDs e sítios da internet de documentos históricos têm sido maneiras para minimizar tais dificuldades.

Desse modo, este trabalho apresenta um exemplo de como dialogar e compartilhar documentos históricos a partir do uso de um Repositório de Conteúdo Digital, um espaço virtual de armazenamento de documentos digitalizados, o qual permite um maior acesso a materiais; visto que a disponibilização das imagens independe de compra de CDs ou DVDs ou até mesmo de cadastro online para utilização e download da documentação.

O modelo de compartilhamento de documentos que apresentaremos nesta comunicação foi idealizado, produzido e está sendo mantido por integrantes do GHEMAT Grupo de Pesquisa em História da Educação Matemática no Brasil - trata-se do Repositório de Conteúdo Digital da História da Educação Matemática ${ }^{l}$, uma biblioteca digital de documentos e materiais relevantes à história da educação matemática.

O GHEMAT, criado no ano de 2000, é cadastrado no Diretório de Grupos de Pesquisas do CNPq, e possui como líderes os professores Neuza Bertoni Pinto (PUC-PR) e Wagner Rodrigues Valente (UNIFESP - Campus Guarulhos) ${ }^{2}$. Atualmente formado por mais de 30 pesquisadores e 70 estudantes (dentre doutorandos, mestrandos e alunos de graduação), o GHEMAT se destaca ${ }^{3}$ pelo desenvolvimento coletivo de projetos temáticos de pesquisa sobre história da educação matemática e possui o objetivo de desenvolver pesquisas na busca de compreensão histórica do ensino e aprendizagem da matemática, da formação de professores de matemática e do processo de constituição da matemática escolar (COSTA, 2015).

Deste modo, com a finalidade de divulgar o armazenamento, preservação, difusão e usos de documentos e materiais do Repositório de Conteúdo Digital da História da Educação Matemática, este texto está organizado em duas partes: a primeira com a apresentação e

\footnotetext{
${ }^{1}$ Disponível em <https://repositorio.ufsc.br/handle/123456789/1769>. Acesso em 08 de julho de 2015.

${ }^{2}$ Mais informações em <http://www.unifesp.br/centros/ghemat>, acesso em 09 de julho de 2015.

3 Segundo o Diretório de Grupos de Pesquisas do CNPq, disponível em: <http://dgp.cnpq.br/dgp/espelhogrupo/2116509882385976>. Acesso em: 20 nov. 2015.
} 
caracterização do Repositório e a segunda com a discussão da prática de pesquisas fundamentadas nos documentos disponíveis nesta biblioteca digital.

\section{O REPOSITÓRIO DE CONTEÚdO DIGITAL DA HISTÓRIA DA EDUCAÇÃO MATEMÁTICA: APRESENTAÇÃO E CARACTERIZAÇÃO}

Com o seu nascimento muito próximo à consolidação do projeto $A$ constituição dos saberes elementares matemáticos: a Aritmética, a Geometria e o Desenho no curso primário em perspectiva histórico-comparativa, 1890-1970, coordenado pelo Prof. Dr. Wagner Rodrigues Valente e financiado pelo CNPq, o Repositório possui o objetivo de solidificar a perspectiva de pesquisas do GHEMAT de trabalho coletivo, e vem sendo mantido com o auxílio desse projeto. Vale ressaltar que o Repositório de Conteúdo Digital está alocado no sítio da Universidade Federal de Santa Catarina, sob a coordenação geral do Prof. Dr. David Antonio da Costa, docente desta instituição, e por isso trata-se de uma ferramenta institucional, de uso, manutenção e colaboração de quaisquer grupos e pesquisadores que se interessarem pelo aprofundamento em pesquisas sobre história da educação matemática.

O projeto do GHEMAT, com início em 2012, já arrecadou mais de dois mil documentos $^{4}$ dentre: programas de ensino, regulamentos para instrução pública, leis e decretos voltados para educação primária e até mesmo referentes ao ensino dos professores primários (Escola Normal); impressos pedagógicos para professores, revistas com orientações didáticas para o ensino, livros e manuais didáticos matemáticos, fotografias, relatórios de instrução pública, materiais de alunos e também anais de alguns eventos.

Além dos documentos históricos, este sítio também disponibiliza referências históricas, referências para história global e para a história conectada, teses e dissertações referentes à história da educação matemática.

\footnotetext{
4 Como o Repositório é um site dinâmico, os números de inserções variam, pois a cada dia pode-se ter novos documentos inseridos. Atualmente, no total, o Repositório conta com 2260 documentos, esse número é obtido a partir da soma da quantidade de documentos obtidos de cada estado (1627 no total) acrescido aos documentos das outras coleções, visto que além das aqui discutidas do projeto $\mathrm{CNPq}$, existe a subcomunidade "A MATEMÁTICA NA FORMAÇÃO DO PROFESSOR DO ENSINO PRIMÁRIO - em tempos do escolanovismo, 1930-1960: fontes para a pesquisa", com 376 documentos e outras coleções com 257 documentos.
} 
Figura 1 - Página do Repositório de Conteúdo Digital da História da Educação Matemática.

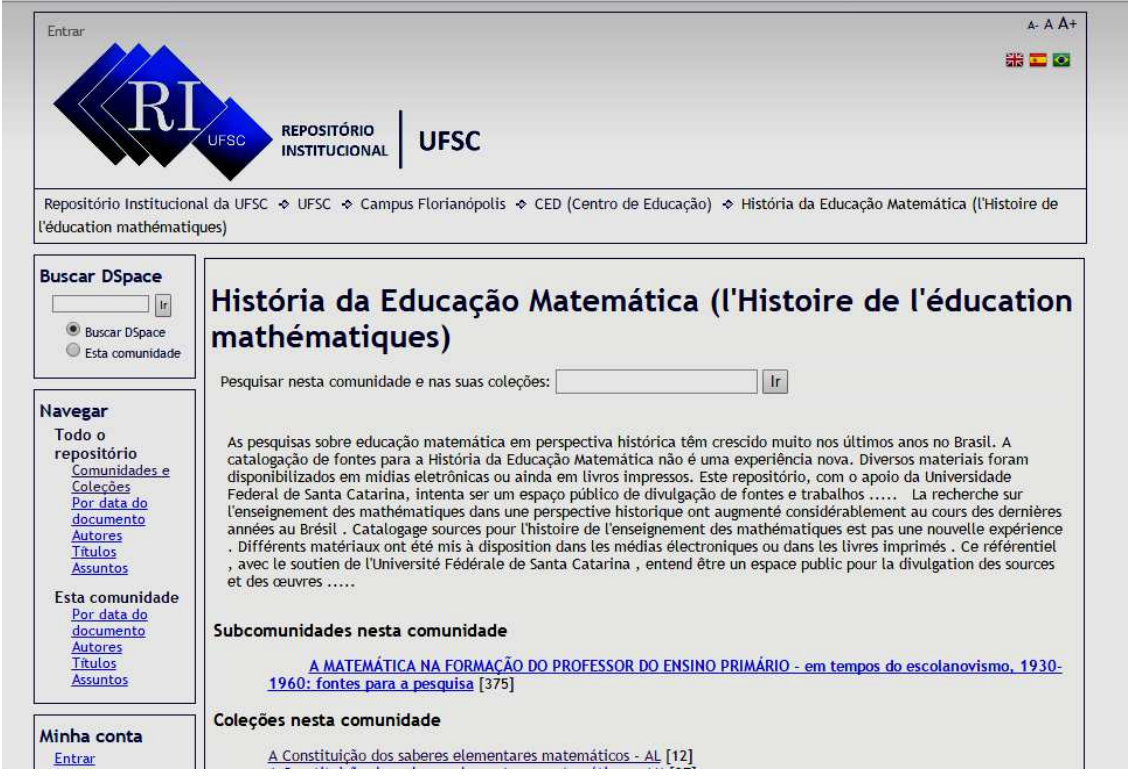

Fonte: <https://repositorio.ufsc.br/handle/123456789/1769>.

Atualmente participam do projeto dezenove estados brasileiros: Alagoas, Amazonas, Bahia, Espírito Santo, Goiás, Maranhão, Minhas Gerais, Mato Grosso, Mato Grosso do Sul, Pará, Paraná, Paraíba, Rio de Janeiro, Rio Grande do Norte, Rio Grande do Sul, Roraima, Santa Catarina, Sergipe e São Paulo; além do Distrito Federal. Na Figura 2 estão demarcados os números de documentos ${ }^{5}$ por estado, disponibilizados no Repositório.

\footnotetext{
${ }^{5}$ Os dados apresentados são com base na consulta às subcomunidades de cada Estado, realizada ao sítio do Repositório em 25 de novembro de 2015.
} 
Figura 2 - Número de documentos por Estado.

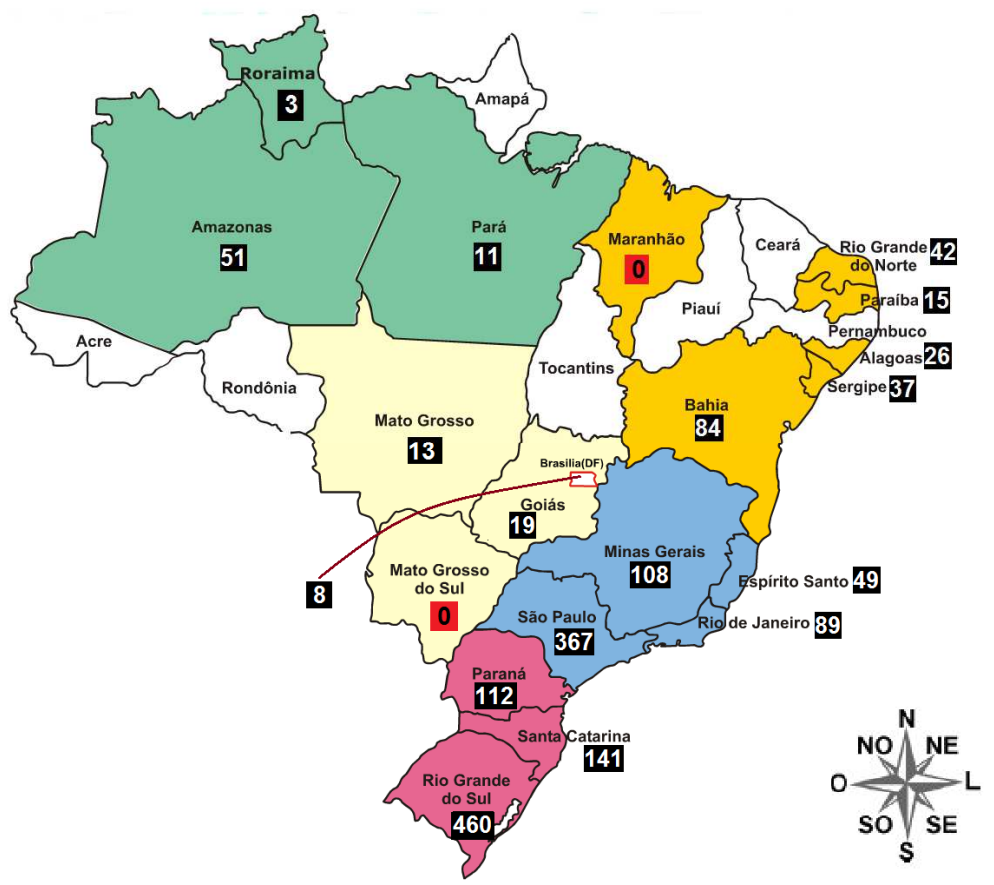

Fonte: elaborado pelas autoras.

Cada estado é responsável por abastecer seu próprio banco de dados/imagens, assim o trabalho é feito totalmente em conjunto, e depende da colaboração dos pesquisadores locais. A busca e a catalogação de documentos deste projeto organizam-se em três etapas principais derivadas do projeto $\mathrm{CNPq}$, que em um primeiro momento concentrou-se primordialmente nas diretrizes oficiais, incluindo programas de ensino, leis e documentos escolares; posteriormente, direcionou-se aos impressos pedagógicos e às revistas; e por fim o levantamento e disponibilização de livros e manuais didáticos de ensino de matemática; sendo todos esses relativos ao ensino primário.

As etapas são orientadas por um procedimento padrão, regido por quatro fases: o levantamento (busca dos documentos em centros históricos, bibliotecas e/ou arquivos), obtenção das cópias (a partir de fotografias, cópias dos originais, microfilmagem ou escaneamento dos documentos de modo a agredir minimamente o original), a catalogação (realização de ficha catalográfica contendo os metadados $^{6}$ necessários para a inserção) e finalmente a disponibilização no Repositório. Assim, para garantir uma melhor difusão dos documentos, algumas de suas informações são imprescindíveis sobre o material.

Um espaço virtual para alocação de documentos digitalizados, estrutura-se na forma de "comunidades", em que cada comunidade possui suas "coleções", que por sua vez

\footnotetext{
${ }^{6}$ Os metadados são informações, detalhes sobre o documento, tal como: uso e direitos, informações descritivas, dados estruturais, etc. (COSTA; VALENTE, 2015).
} 
possuem "itens" que representam os conteúdos digitais. Assim, o Repositório de Conteúdo Digital da História da Educação Matemática constitui assim uma comunidade, com coleções e itens de diversos estados brasileiros, com o intuito de que tais documentos digitais tornemse fontes de pesquisa na busca de elaboração de um conhecimento glocal, entendido segundo Chartier (2010) como a articulação de produções locais com discussões em perspectivas globais.

\footnotetext{
A união indissociável do global e do local levou alguns a propor a noção de "glocal", que designa com correção, se não com elegância, os processos pelos quais são apropriadas as referências partilhadas, os modelos impostos, os textos e os bens que circulam mundialmente, para fazer sentido em um tempo e em um lugar concretos. (CHARTIER, 2010, p. 57).
}

Dessa forma, é possível, por exemplo, que pessoas que estejam na região sul do país possam fazer uso de documentos da região norte sem obrigatoriamente sair do seu estado, pois não há mais limites geográficos para se consultar fontes de pesquisa (COSTA, 2015).

Cada estado possui uma "coleção" específica na comunidade "História da Educação Matemática" para alocação e disponibilização dos documentos encontrados. No caso do estado de São Paulo, para cada documento encontrado, fazemos uma ficha catalográfica, como exemplifica a Figura 3, em que são destacados: o título do documento devidamente identificado com data, ano, volume e estado em que se encontra; a citação bibliográfica conforme as normas da ABNT; uma breve descrição do documento no qual são informadas características físicas do material, além de quantidade de páginas e local de obtenção da cópia autorizada; um resumo do documento com a finalidade de destacar os aspectos relativos ao curso primário e ao ensino de matemática, visto que esses são os temas relativos à disponibilização de documentos neste Repositório; a editora em que foi publicado o documento; e por fim, algumas palavras-chave que auxiliam o pesquisador quando se realiza uma busca no sítio do Repositório. Essa ficha catalográfica devidamente preenchida auxilia na inserção do documento no site do Repositório. 
Figura 3 - Ficha catalográfica.

\begin{tabular}{|c|c|}
\hline Título & A Eschola Publica 1823, Volume I, n.2. Agosto, SP. \\
\hline Citação & $\begin{array}{l}\text { A ESCHOLA PUBLICA. São Paulo, SP: Typ Hennies e Winiger, v. I, n. } \\
\text { 2.Agosto, } 1823 \text {. Mensal. }\end{array}$ \\
\hline Descrição & $\begin{array}{l}\text { Estas imagens foram obtidas a partir do Acervo da Faculdade de Educação } \\
\text { USP. }\end{array}$ \\
\hline Resumo & $\begin{array}{l}\text { Este arquivo refere-se ao segundo número da Revista A Eschola Publica em } \\
\text { sua primeira fase. O qual apresenta os seguintes artigos em destaques: } \\
\text { p. } 11 \text { - A Arithmetica Elementar II: De autoria de Oscar Thompson, o } \\
\text { artigo descreve alguns exercicios escritos para ensinar as crianças a ler e } \\
\text { escrever todos os algarismos, e destaca que cada lição escrita deve preceder } \\
\text { uma outra oral; } \\
\text { p.12 - Primeiras lições de Desenho II: B.M. Tolosa, em continuidade ao do } \\
\text { número anterior (n.1 Vol.1), apresenta lições para o ensino das linhas, o } \\
\text { texto apresenta algumas ilustrações de linhas verticais e horizontais; } \\
\text { p. } 16 \text { - Taboada: Oscar Thompson apresenta um modo de ensinar a tabuada } \\
\text { usando os tornos, ou os grãos de feijão, ou de arroz; }\end{array}$ \\
\hline Editora & Typ Hennies e Winiger \\
\hline $\begin{array}{l}\text { Palavra- } \\
\text { chave }\end{array}$ & Ensino primário \\
\hline $\begin{array}{l}\text { Palavra- } \\
\text { chave }\end{array}$ & Aritmética \\
\hline $\begin{array}{l}\text { Palavra- } \\
\text { chave }\end{array}$ & Ensino de Desenho \\
\hline $\begin{array}{l}\text { Palavra- } \\
\text { chave }\end{array}$ & Tabuada \\
\hline
\end{tabular}

Fonte: Arquivo Pessoal.

Essa indexação, quando disponibilizada juntamente ao documento no sítio do Repositório, auxilia o pesquisador que busca documentos relativos à história da educação matemática, com algumas opções de procura: por data do documento; autores; títulos; e assuntos. Cada item presente no Repositório está associado e identificado por seus metadados, que permitem mobilizar mecanismos de busca no $\operatorname{DSpace}^{7}$, possibilitando que o pesquisador acesse a informação antes mesmo de ver suas imagens, conforme a Figura 4.

7 DSpace é um mecanismo de busca, desenvolvido em parceria com MIT - Massachusetts Institute of Technology e a Hewlett Packard Corporation. Para maiores detalhes ver: COSTA, D. A.; ARRUDA, J. P. (2012). 
Figura 4 - Metadados disponibilizados no Repositório.

\begin{tabular}{|c|c|c|c|c|}
\hline \\
\hline dc.contributor.author & \multicolumn{4}{|l|}{ Não identificado } \\
\hline dc.date.accessioned & \multicolumn{4}{|l|}{ 2015-07-05T13:09:11Z } \\
\hline dc.date.available & \multicolumn{4}{|l|}{ 2015-07-05T13:09:11Z } \\
\hline dc.date.issued & \multicolumn{4}{|c|}{1952} \\
\hline dc.identifier.citation & \multicolumn{3}{|c|}{$\begin{array}{l}\text { BOLETIM DA SECRETARIA DA EDUCAÇ̃̃o DO ESTADO DE SÃO PAULO. São Paulo, SP: } \\
\text { Serviço de Legislação e Publicidade, } n .7 \text { e } 8,1952 \text {. }\end{array}$} & pt_BR \\
\hline dc.identifier.uri & \multicolumn{4}{|c|}{ https://repositorio.ufsc.br/xmlui/handle/123456789/133614 } \\
\hline dc.description & \multicolumn{3}{|c|}{$\begin{array}{l}\text { Estas imagens foram obtidas no acervo disponivel pelo Centro do Professorado Paulista } \\
\text { (CPP). }\end{array}$} & pt_BR \\
\hline dc.description.abstract & \multicolumn{3}{|c|}{ 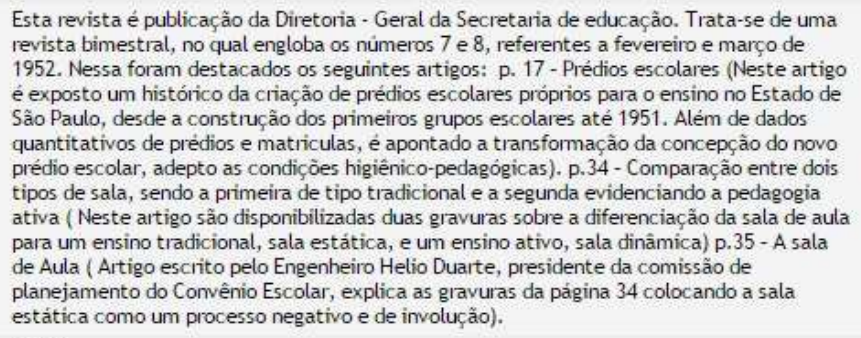 } & pt_BR \\
\hline dc.language.iso & \multicolumn{3}{|c|}{ pt_BR } & $\mathrm{pt} \_B R$ \\
\hline dc.publisher & \multicolumn{3}{|l|}{ Serviço de Legislação e Publicidade } & pt_BR \\
\hline dc.subject & \multicolumn{3}{|l|}{ Ensino Primário } & $\mathrm{pt} \_\mathrm{BR}$ \\
\hline dc.subject & \multicolumn{3}{|c|}{ Prédios Escolares } & pt_BR \\
\hline dc.title & \multirow{2}{*}{\multicolumn{3}{|c|}{ Boletim da Secretaria da Educação do Estado de São Paulo, 1952, ano 1, n.7 e 8, SP. }} & $\mathrm{pt} \_\mathrm{BR}$ \\
\hline dc.type & \multicolumn{2}{|c|}{ Other } & & pt_BR \\
\hline \multicolumn{5}{|c|}{ Arquivos } \\
\hline \multicolumn{2}{|c|}{ Boletim da Secr... aulo - 1952 -n. 7 e 8.PDF } & PDF & Visualizar/Abrir & odf \\
\hline
\end{tabular}

Fonte: <https://repositorio.ufsc.br/handle/123456789/133614>.

Até o dia 20 de novembro de 2015, o site já apresentou mais de 12600 visualizações, entre os países que já o acessaram encontram-se além do Brasil, Estados Unidos, China, Alemanha, Japão, Ucrânia, Países Baixos, França e Portugal $^{8}$. Isso permite inferir que a catalogação e divulgação de livre acesso aos conteúdos digitais de diversos estados com sua multiplicidade de fontes têm contribuído na dinâmica de elaboração de estudos históricos.

\section{PRÁtiCAS DE PESQUiSA DO GHEMAT DA HISTÓRIA DA EDUCAÇÃo MATEMÁTICA A PARTIR DO REPOSITÓRIO}

Para que as pesquisas realizadas e em andamento do GHEMAT sejam de conhecimento de todo o grupo, são realizados Seminários Temáticos. Desde 2006 já foram realizados doze seminários ${ }^{9}$ e já está prevista a próxima edição, para março de 2016 . O

\footnotetext{
${ }^{8}$ Dados obtidos do próprio site do Repositório de Conteúdo Digital da História da Educação Matemática.

${ }^{9}$ Mais informações sobre as edições anteriores dos Seminários Temáticos, como local, anais, links de acesso, podem ser facilmente encontradas na página do GHEMAT <http://www.unifesp.br/centros/ghemat/paginas/teses.htm>.
} 
projeto em questão, em que associa-se a manutenção e inserção de documentos no Repositório que explicitamos anteriormente, promovera três seminários temáticos, sendo eles: a $11^{\text {a }}$ edição que ocorreu em Florianópolis/SC, no ano de 2014; a $12^{\mathrm{a}}$ edição no início do ano de 2015 em Curitiba/PR; e a 13ª edição que está prevista para março de 2016, na cidade de Natal/RN.

Esses Seminários têm o intuito de oferecer um espaço para debate e estudo, nos quais professores e alunos (de graduação ou pós-graduação) integrantes do GHEMAT apresentam suas pesquisas e discutem abertamente seus trabalhos, teorias e documentação. As apresentações são direcionadas por um coordenador pré-determinado - encarregado de ler os trabalhos previamente - que abre a discussão a partir de suas concepções sobre a pesquisa apresentada. Essa estrutura utilizada pelo grupo permite que todos apontem aspectos positivos ou negativos na pesquisa dos demais, promovendo aprendizagem e troca de ideias.

De fato, os Seminários Temáticos organizados pelo GHEMAT, têm-se revelado como importantes momentos de discussão e reflexão acerca dos resultados parciais que vêm sendo obtidos com a realização dos projetos de estudos compartilhados. Com a utilização dos documentos postos no Repositório, aumentaram os resultados que evidenciam pesquisas comparativas devido à possibilidade de interação com documentos em nível nacional. Os dois últimos Seminários Temáticos foram subsidiados pela documentação disponibilizada no Repositório de Conteúdo Digital da História da Educação Matemática, referentes às etapas do projeto $\mathrm{CNPq}$, o primeiro privilegiou os arquivos oficiais, enquanto o segundo buscou relacionar revistas pedagógicas e documentos oficiais $\left(11^{\mathrm{a}}\right.$ e $12^{\mathrm{a}}$ edições, respectivamente).

A seguir serão disponibilizados mais elementos sobre o XI e XII Seminários Temáticos, que fomentam práticas de pesquisa realizadas com o uso do Repositório de Conteúdo Digital.

\section{O XI SEMINÁRIO TEMÁTICO}

O XI Seminário Temático intitulado A Constituição dos Saberes Elementares Matemáticos: A Aritmética, a Geometria e o Desenho no curso primário em perspectiva histórico-comparativa, 1890-1970, como já explicitado anteriormente, ocorreu na cidade de Florianópolis, em Santa Catarina, no ano de 2014. Neste evento, foram apresentadas duas modalidades de trabalho, os resumos e os artigos completos. No total foram expostos trinta e um resumos e vinte artigos completos em apenas três dias de Seminário, além da Mesa de 
discussão temática, acerca do tema "Perspectivas teórico-metodológicas para a pesquisa em História da Educação hoje”, proferida pelas professoras doutoras: Maria Helena Câmara Bastos (PUC/RS) com seu trabalho "Um protocolo para a pesquisa em História da Educação: espaços, sujeitos e circulação"; Maria Tereza Santos Cunha (UDESC/SC) e seu estudo "Um protocolo para a pesquisa em História da Educação: espaços, sujeitos e circulação"; e Maria Bernardete Ramos Flores (UFSC/SC) com sua pesquisa "A potência do anacronismo: tempo e distempo na prática historiográfica".

Com uma estrutura diferenciada, todos os trabalhos submetidos a esse Seminário não tiveram apresentação do texto pelo autor, os trabalhos foram disponibilizados anteriormente no site do evento para conhecimento de todos os participantes e leitura. Nas seções, um avaliador era responsável por levantar questionamentos e comentários sobre os textos que ficaram sob a sua responsabilidade e em seguida era aberta a discussão para os demais presentes. Vale ressaltar que essa dinâmica só se tornou possível pois foi estruturada sem qualquer choque de horário com outras seções ou palestras e conferências, assim todos os participantes tiveram oportunidade de estarem presentes e assistirem a todas as discussões e apresentações.

$\mathrm{Na}$ leitura dos anais $^{10}$ desse Seminário é possível evidenciar que o uso dos documentos normativos como fontes, compartilhados no Repositório, possibilitou enredar várias temáticas de estudo. Encontram-se resultados de pesquisas sobre o ensino primário, entre eles, conteúdos específicos, métodos de ensino, recursos adotados para a instrução de saberes matemáticos, avaliação, formação de professores, práticas de ensino e resolução de problemas. Independente de o estudo ter sido desenvolvido por alunos da graduação, mestrandos e/ou doutorandos ou até mesmo professores doutores, o que caracteriza nesse cenário é a possibilidade de dialogar com as fontes do outro. Essa troca de documentações evidenciada pelo uso desta biblioteca digital é revelada em diversos trabalhos apresentados no Seminário.

Para expor sobre o que os documentos normativos possibilitaram dizer da história do ensino dos saberes elementares matemáticos na instrução primária, tomaremos três trabalhos característicos, por enredarem legislações e documentos oficiais de distintas regiões do Brasil e até mesmo da França. O primeiro deles denominado "Geometria e Desenho na formação de professores primários no Brasil e na França, 1890 - 1970: o que dizem as normativas oficiais?", de autoria da professora doutora Maria Cristina Araújo de Oliveira, apresenta em

\footnotetext{
${ }^{10}$ Os anais desse seminário podem ser acessados em <http://seminariotematico.ufsc.br/category/artigos/>.
} 
seu estudo, mediante o uso dos programas oficiais de diferentes estados brasileiros e documentos franceses, o seu plano de estudo de pós-doutoramento em desenvolvimento na Université de Paris 11, que tem a temática: Formação de Professores Primário. Com este artigo, a autora inicia sua pesquisa de caráter histórico-comparativo, com o intuito de investigar a que objetivos respondem a inclusão da Geometria e do Desenho na formação dos professores primários no Brasil e na França no período de 1890 a 1970.

O segundo artigo intitulado "Os Saberes Elementares Matemáticos, Geometria e Desenho, nos Programas Oficiais: um estudo dos documentos de São Paulo, Sergipe e Goiás contidos no repositório virtual", de autoria de Marcos Denilson Guimarães e Maria Célia Leme da Silva, apresenta uma análise dos programas oficiais de ensino dos estados de São Paulo, Sergipe e Goiás referentes às trajetórias de constituição dos saberes elementares, desenho e geometria. Para mais, o texto apresenta uma discussão sobre como os programas dialogam com as ideias do método intuitivo e/ou ativo de ensino, já que são tomados para análise, programas até a década de 1930.

O terceiro trabalho, de autoria do professor doutor Wagner Rodrigues Valente, intitulado "A Pedagogia Científica e os Programas de Ensino de Matemática para o Curso Primário: uma análise dos documentos do repositório de conteúdo digital, 1930-1950" apresenta como objetivo de responder a seguinte questão: O que dizem os programas de ensino de diferentes estados em termos da circulação e apropriação dessas referências da pedagogia científica para a educação matemática? Com o uso do Repositório, o autor utilizou programas dos estados de Goiás, Minas Gerais, Paraná, São Paulo, Espírito Santo, Alagoas e Mato Grosso em conjunto com documentos acerca da Pedagogia Científica, como Binet (2010) e Lourenço Filho (1930).

A partir desses três trabalhos supracitados é possível constatar características e contribuições acerca da produção fundamentada na legislação. O uso do Repositório possibilitou aos autores a aproximação entre as regiões, estados e países, e assim, fomentou a articulação de debates históricos comparativos. Os documentos foram analisados sobre distintos olhares, seja para a compreensão de saberes específicos, dos métodos ou dos recursos. $\mathrm{O}$ acesso às fontes digitalizadas contribuiu para o aumento da produção acerca do ensino primário.

Além desses artigos que possibilitaram o olhar a distintas regiões, outros trabalhos de caráter local também tiveram espaço para discussão neste Seminário. Dentre eles destacamos 
dois que mesmo se tratando de um único estado cada, trazem análises de muitos programas, e assim abarcam um período de maior fôlego.

São eles: o artigo intitulado "Grupos Escolares Paulistas (1893-1971): as transformações dos saberes geométricos nos programas de ensino primário", de autoria de Claudia Regina Boen Frizzarini e Maria Célia Leme da Silva. As autoras se prepuseram a investigar as transformações que ocorreram no ensino primário paulista ao que diz respeito às matérias de ensino que se referem aos saberes geométricos, e que vigoraram durante o período em que se instalaram os Grupos Escolares, observando assim oito programas de ensino de São Paulo.

O outro trabalho é de Jefferson dos Santos Ferreira e Ivanete Batista dos Santos, “Saberes Elementares Aritméticos na Escola Primária em Sergipe: uma Investigação Sobre Conteúdos, Métodos e Recursos (1901-1931)”, apresentou os resultados da pesquisa que visou compreender como os saberes elementares aritméticos foram propostos em documentos legais, de forma a identificar elementos de mudança e continuidade no que diz respeito aos conteúdos, métodos e recursos no período de 1901 a 1931.

Para além dos mais de cinquenta trabalhos produzidos nesse seminário, o XI Seminário Temático resultou na elaboração do livro "Saberes matemáticos no curso primário: o que, como e por que ensinar? Estudos histórico-comparativos a partir da documentação oficial escolar" (Figura 5) organizado pelos professores David Antonio da Costa e Wagner Rodrigues Valente.

Figura 5: Livro elaborado a partir da realização do XI Seminário.

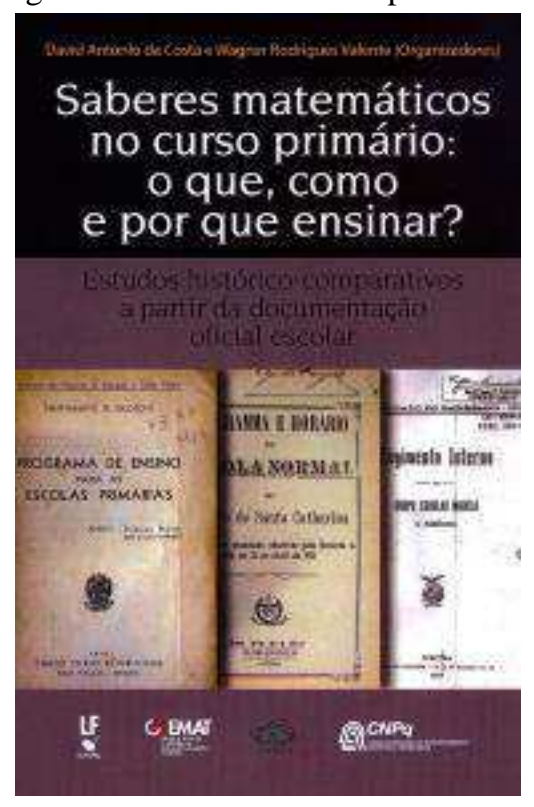

Fonte: Arquivo Pessoal. 
Neste livro ${ }^{11}$, cada capítulo é organizado por um estado brasileiro (sendo eles: Alagoas, Bahia, Espírito Santo, Minas Gerais, Paraná, Rio de Janeiro, Rio Grande do Sul, Santa Catarina, São Paulo e Sergipe), elaborado a partir dos artigos apresentados no seminário, por fim são construídas considerações finais a todos os capítulos, em que é ressaltada a complexidade de se elaborar estudos histórico-comparativos, e a necessidade de construção de estudos imbricando o local e o global, olhando ao micro e ao macro simultaneamente, como propõe o historiador Roger Chartier (2010) na busca de estudos em parâmetro glocal, em que se articulam produções locais com discussões em perspectivas ampliadas.

\section{O XII SEMINÁRIO TEMÁTICO}

O XII Seminário Temático intitulado "Saberes elementares matemáticos do ensino primário (1890 - 1970): o que dizem as Revistas Pedagógicas?” pertencente à segunda etapa do projeto CNPq ocorreu em Curitiba no ano de 2015 e privilegiou as revistas pedagógicas como fontes de pesquisa.

Nesse encontro só foram apresentados artigos em formato completo, em um total de 61 trabalhos. Também realizado em três, uma mesa de discussão foi posta a cada um dos dias, como abertura dos trabalhos, sendo elas: Mesa 1 - História da Leitura, da Escrita e do Contar, proferida pelos professores doutores Vera Teresa Valdemarin (UNESP/SP) com seu estudo "Renovação dos métodos de ensino e formação de professores: entre a história e a pedagogia" e Wagner Rodrigues Valente (UNIFESP/SP) com "Renovação dos métodos de ensino de matemática: entre a história, a matemática e a pedagogia”; Mesa 2 - História Comparativa, composta por Mirian Jorge Warde (UNIFESP/SP) com sua palestra "Alguns problemas implicados no uso da comparação como método e como abordagem" e Rosa Fátima de Souza (UNESP/SP) expondo sobre sua pesquisa "Investigações Comparadas sobre a História da Escola Primária no Brasil (1930 - 1961): notas em torno de uma trajetória de pesquisa"; e Mesa 3 - História dos Grupos Escolares, de Sidney Reinaldo da Silva (IFPR/PR) com "Saber Elementar e Emancipação segundo Condorcet" e Rosa Lydia T. Corrêa (PUCPR/PR) sobre “Grupos Escolares no Paraná (1903 - 1950): algumas considerações”.

11 Esse livro também está disponível na versão e-book em <https://repositorio.ufsc.br/handle/123456789/133058>, acesso em 14 de outubro de 2015. 
As mesas propostas além de, por si próprias, trazerem pesquisas de distintos temas e estados, fomentaram teórica e metodologicamente as discussões por serem proferidas por doutores que já buscam construir estudos a partir de história comparada e que já trabalham proficuamente sobre o ensino primário brasileiro.

Os artigos, assim como no XI Seminário Temático, não foram apresentados por seus autores, no entanto, nesse Seminário o uso do Repositório tornou-se mais evidente, muitos trabalhos quando abertos ao debate foram indagados por dois motivos: as revistas que mencionaram no texto não estavam presentes no Repositório e por isso os leitores não puderam constatar as afirmações do autor, ou ainda por as revistas já estarem disponibilizadas e assim o debate sobre as conclusões a partir das documentações se intensificarem.

Para os trabalhos que foram produzidos nesse seminário também possui a intenção de elaborar e publicar outro livro, sob o título ainda provisório "Saberes elementares matemáticos em circulação no Brasil: dos documentos oficiais às revistas pedagógicas, 18901970”, que está sendo organizado pelos professores Neuza Bertoni Pinto e Wagner Rodrigues Valente. O objetivo da publicação desse livro é sistematizar os resultados de pesquisa obtidos até o momento, juntamente com o desenvolvimento do projeto já mencionado “A constituição dos saberes elementares matemáticos: a Aritmética, a Geometria e o Desenho no curso primário em perspectiva histórico-comparativa, 1890-1970”. A priori o livro será constituído de dez capítulos, cada qual com discussões sobre uma temática em comum, podendo haver diferentes estados envolvidos. O livro está previsto para ser lançado no XIII Seminário Temático, em março de 2016, na cidade de Natal/RN.

Acreditamos que nesse XII Seminário Temático, além da importância de construção de uma história comparativa com o intuito de compreendermos o glocal, percebemos que o Repositório de Conteúdo Digital da História da Educação Matemática auxilia na comprovação dos fatos, dos dados, das conclusões. O historiador Bloch (2001) há muito tempo reflete sobre a veracidade dos documentos, e mais ainda sobre a credibilidade da palavra das testemunhas, visto que nem todos os relatos são verdadeiros e os vestígios e provas também podem ser falsificados, mas, além disso, as afirmações sobre as fontes podem ser equivocadas, e o Repositório contribui para essa troca de documentação e possibilidade de novas apropriações $^{12}$ de um mesmo documento obtendo novas representações ${ }^{13}$ e uma história mais fidedigna.

\footnotetext{
${ }^{12}$ A apropriação, tal como a entendemos, tem por objetivo uma história social das interpretações, remetidas para as suas determinações fundamentais (que são sociais, institucionais, culturais) e inscritas nas práticas específicas que as produzem. Conceder deste modo atenção às condições e aos processos que, muito concretamente, 


\section{ALGUMAS CONSIDERAÇÕES}

Este capítulo teve o intuito de apresentar o Repositório de Conteúdo Digital da História da Educação Matemática, uma ferramenta virtual utilizada para alocar documentos históricos a fim de que pesquisadores obtenham acesso livre a esses arquivos em nível mundial. A intenção é proporcionar a disseminação desses documentos para a pesquisa em história da educação matemática, e para isso é necessário que o Repositório se torne um instrumento de pesquisa e consulta para outros pesquisadores, além dos integrantes do GHEMAT.

Através do projeto financiado pelo $\mathrm{CNPq}$, até o momento foi possível realizar dois Seminários Temáticos, com previsão para o terceiro, em março de 2016. Esses Seminários discutem pesquisas realizadas ou em andamento a partir dos documentos disponibilizados no Repositório, e servem principalmente para a divulgação científica nacional.

Como resultados do XI Seminário Temático, temos que o Repositório permitiu que diferentes estados e regiões se aproximassem através das discussões proporcionadas, estimulando e incentivando a articulação em debates sobre pesquisas histórico-comparativas. No XII Seminário Temático, pudemos perceber que o Repositório ajuda a comprovar os dados e as conclusões tomadas a partir da análise de arquivos que seriam de difícil acesso, mas que ao serem digitalizados, qualquer pessoa pode consultá-los.

Após essa explanação, podemos inferir que os estudos por meio dos documentos postos no Repositório proporcionaram um aumento da produção científica sobre o ensino primário brasileiro relacionado aos saberes elementares matemáticos, trazendo características da escola primária em tempos passados, seja de elementos da sua constituição, organização e espaço, seja referente ao ensino de saberes matemáticos, métodos de ensino, orientações pedagógicas e finalidades de ensino. Diante o exposto, o Repositório também serve como exemplo de instrumento para pesquisas de outras temáticas, para armazenamento e divulgação de documentos históricos, independente de limites geográficos.

determinam as operações de construção do sentido (na relação de leitura, mas em muitas outras também) é reconhecer, contra a antiga história intelectual, que as inteligências não são desencarnadas, e, contra as correntes de pensamento que postulam o universal, que as categorias aparentemente mais invariáveis devem ser construídas na descontinuidade das trajetórias históricas (CHARTIER, 2002, p. 27).

${ }^{13}$ As representações do mundo social assim constituídas, embora aspirem à universalidade de um diagnóstico fundado na razão, são sempre determinadas pelos interesses de grupo que as forjam. Daí, para cada caso, o necessário relacionamento dos discursos proferidos com a posição de quem os utiliza (CHARTIER, 2002, p. 17). 


\section{REFERÊNCIAS}

BLOCH, Marc. Apologia da história: ou, O ofício de historiador. Rio de Janeiro: Jorge Zahar, 2001.

CHARTIER, Roger. A história cultural - entre práticas e representações. Lisboa: Difel; Rio de Janeiro: Bertrand, 2002.

A história ou a leitura do tempo. 2. ed. Belo Horizonte: Autêntica, 2010.

COSTA, David Antonio da. Repositório. In: VALENTE, W.R. (Org.). Cadernos de Trabalho. v. 3, São Paulo: Livraria da Física, 2015.

COSTA, D. A.; ARRUDA, J. P. Repositório institucional de fontes para história da educação matemática na Universidade Federal de Santa Catarina. In: Anais... I Encontro Nacional de Pesquisa em História da Educação Matemática- I ENAPHEM. Vitória da Conquista: UESB, 2012.

COSTA, David Antonio da; VALENTE, Wagner Rodrigues (Orgs.). Saberes matemáticos no curso primário: o que, como e por que ensinar? Estudos histórico-comparativos a partir da documentação oficial escolar. São Paulo: Livraria da Física, 2014. Em linha (ebook): <https://repositorio.ufsc.br/handle/123456789/133058>. Acesso em: 14 jul. 2015.

História da Educação Matemática e o uso de um Repositório de conteúdo digital. Série história da matemática para o ensino; v. 4. São Paulo: Livraria da Física, 2015.

FERREIRA, J. S.; SANTOS, I. B. Saberes Elementares Aritméticos na Escola Primária em Sergipe: uma Investigação Sobre Conteúdos, Métodos e Recursos (1901-1931). In: XI Seminário Temático: A Constituição dos Saberes Elementares Matemáticos, 2014. Florianópolis. Anais... Santa Catarina: UFSC, 2014. Disponível em: <http://seminariotematico.ufsc.br/files/2014/03/ATA2_Ferreira-e-Santos_art_DAC.pdf >. Acesso em: 29 nov. 2015.

FRIZZARINI, C. R. B.; SILVA, M. C. L. Grupos Escolares Paulistas (1893-1971): as transformações dos saberes geométricos nos programas de ensino primário. In: XI Seminário Temático: A Constituição dos Saberes Elementares Matemáticos, 2014. Florianópolis. Anais... Santa Catarina: UFSC, 2014. Disponível em: <http://seminariotematico.ufsc.br/files/2014/03/ASA2_Frizzarini_art_DAC.pdf>. Acesso em: 29 nov. 2015.

GUIMARÃES, M. D.; SILVA, M. C. L. Os Saberes Elementares Matemáticos, Geometria e Desenho, nos Programas Oficiais: um estudo dos documentos de São Paulo, Sergipe e Goiás contidos no repositório virtual. In: XI Seminário Temático: A Constituição dos Saberes Elementares Matemáticos, 2014. Florianópolis. Anais... Santa Catarina: UFSC, 2014. Disponível em: <http://seminariotematico.ufsc.br/files/2014/03/ATB2_Guimar\%C3\%A3es_art_DAC.pdf>. Acesso em: 29 nov. 2015. 
OLIVEIRA, M. C. A. Geometria e Desenho na formação de professores primários no Brasil e na França, 1890 - 1970: o que dizem as normativas oficiais? In: XI Seminário Temático: A Constituição dos Saberes Elementares Matemáticos, 2014. Florianópolis. Anais... Santa Catarina: UFSC, $2014 . \quad$ Disponível em: $<$ http://seminariotematico.ufsc.br/files/2014/04/Geometria-e-Desenho-naforma\%C3\%A7\%C3\%A3o-de-professores.pdf>. Acesso em 29 nov. 2015.

VALENTE, W. R. A Pedagogia Científica e os Programas de Ensino de Matemática para o Curso Primário: uma análise dos documentos do repositório de conteúdo digital, 1930-1950. In: XI Seminário Temático: A Constituição dos Saberes Elementares Matemáticos, 2014. Florianópolis. Anais... Santa Catarina: UFSC, 2014. Disponível em: $<$ http://seminariotematico.ufsc.br/files/2014/03/ATB4_VALENTE_art_DAC.pdf>. Acesso em 29 nov. 2015. 